\title{
In vitro Acetyl Cholinesterase Inhibitory assay of Acacia catechu Willd Ethanolic Seed Extract
}

\author{
Lakshmi Thangavelu ${ }^{* 1}$ and Rajendran Ramasamy ${ }^{2}$ \\ 'Department of Pharmacology, Saveetha Dental College and Hospitals, Chennai, India. \\ ${ }^{2}$ Green Chem Herbal Extracts and Formulations, Bangalore, India.
}

\begin{abstract}
Aim \& objective: The aim of this study was to evaluate acetyl cholinesterase inhibitory activity of Acacia catechu ethanolic seed extract to introduce a new source for management of Alzheimer's disease. Background: Alzheimer's disease is a complex, multifactorial, progressive, neurodegenerative disease primarily affecting the elderly population and is estimated to account for $50-60 \%$ of dementia cases in persons over 65 years of age. It is likely that the inhibition of acetyl cholinesterase by Acacia catechu ethanolic seed extract that is rich in flavonoids and antioxidants may aid in the protection of neurodegenerative disorders and ultimately Alzheimer's disease. Methods: Anti cholinesterase activity is determined by adopting In vitro standard protocol. Results: According to the obtained results, the inhibitory activity $\left(I C_{50}\right.$ values, $\left.\mu \mathrm{g} / \mathrm{ml}\right)$ of extracts was $204.38 \pm 2.54 \mu \mathrm{g} /$ $\mathrm{ml}$. Conclusion: The results indicated and confirmed the traditional use of Acacia catechu ethanolic seed extract for management of central nervous system disorders. It showed the moderate activity in inhibition of acetyl cholinesterase at various concentrations. However, further investigations on identification of active components in the extracts are needed.
\end{abstract}

Key words: Acacia catechu seed, Acetyl cholinesterase inhibitor, Alzheimer's disease, Neurodegenerative, Spectrophotometric analysis.

\section{SUMMARY}

- Acacia catechu Willd. Belongs to the family fabacaae Commonly known as khadira in Sanskrit and karungali in Tamil is a very potent medicinal plant with diverse pharmacological actions.

- Alzheimer's disease (AD) is an neurodegenerative disorder affecting people all over the world. It is associated with loss of cholinergic neurons in the brain and decreased level of Ach.
- Acacia catechu seed is rich in Catechin, Epicatechin and it also exhibits significant antioxidant property.

- Acacia catechu seed inhibits Acetyl cholinesterase level hence, recommended for management of Alzheimer's disease.

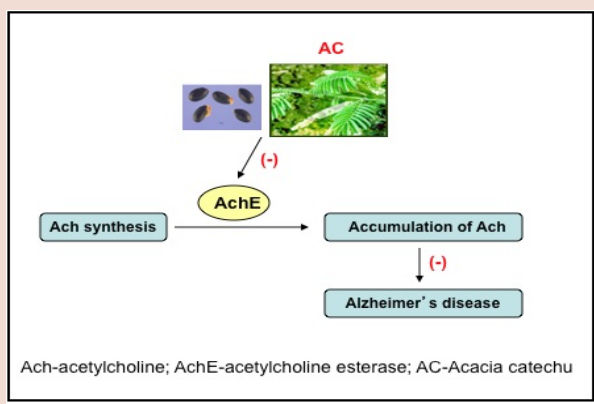

\section{PICTORIAL ABSTRACT}

Abbreviations used: Ach: Acetyl choline, Ache: Acetyl cholinesterase, Ac: Acacia catechu.

Correspondence:

Prof. Lakshmi Thangavelu, Assistant Professor, Department of Pharmacology, Saveetha Dental College and Hospitals, Chennai, India.

Email: lakshmi085@gmail.com

DOI : 10.5530/pj.2015.5.5

\section{INTRODUCTION}

Alzheimer's disease (AD) is an neurodegenerative disorder associated with loss of neurons in the certain areas of brain which leads to cognitive impairment, neurological disturbances, behavioral abnormalities, even leads to death. The pathophysiology of $\mathrm{AD}$ is not clear, but it is believed to be associated with cholinergic pathway impairment, leading to reduction in acetylcholine level in certain regions of the brain. ${ }^{1}$ Acetylcholine, a neurotransmitter, which is hydrolyzed by acetyl cholinesterase (AChE) and butyryl cholinesterase (BuChE) is considered to play an important role in the pathology of $\mathrm{AD}{ }^{2}$

Neuritic plaques (Neurofibrillary tangles, amyloid plaques) are the major structural abnormality in seen commonly in AD patients. Amino acid Beta-amyloid peptide is an chief protein substance of amyloid in AD individuals. ${ }^{3}$ The therapy of $\mathrm{AD}$ depends on decreasing the progression of the disease by improving the quality of life. Inhibition of acetyl choline level may aid in control of $\mathrm{AD}$.

Cognitive enhancers are used in management of $\mathrm{AD}$, Few of the cognitive enhancers are only approved by FDA in united states. ${ }^{4}$ few drugs that have received regulatory approval currently includes donepezil, rivastigmine and galantamine, these drugs acts through increasing the concentration of acetylcholine at the neurotransmitter sites or directs by regulating activity at nicotinic receptors. ${ }^{5}$
Various side effects of medications reported in clinical trials causes nausea, vomiting, diarrhea, syncope and bradycardia. ${ }^{6}$ Absolutely, there requires a fundamental need for an alternative to anti-cholinesterase compounds with fewer side effects that leads to investigation on plants as a novel source of treatment of AD?

Natural sources have been used since antiquity in the treatment of various diseases including cognitive disorders, such as AD.

Considering the importance of plant based compounds in drug discovery, the present study was undertaken to evaluate the anti-cholinesterase activity of a number of selected medicinal plants with various ethno botanical uses, aiming to discover new compounds for anti-cholinesterase activity to be used in management of AD. ${ }^{8-10}$

Acacia catechu (Family: Fabacaae) is an indigenous tree grown in all the parts of the world. Commonly known as karungali in Tamil and khadira in Sanskrit. Similarly to Neem, Turmeric, Aloe Vera, People in Kerala used this karungali leaves in boiling water, extracted juice for management of digestive disorders. ${ }^{11}$ It has been used in Ayurveda (Indian Medicinal System) for years extensively as an anti-inflammatory agent. It has been proven to possess antioxidant, anticancer, antiulcer, hepato protective, anti diabetic effects. ${ }^{12-17}$ It also has a role in dye industry the heartwood of khadira is employed for this purpose. Study reported that 
Table 1: Anti cholinesterase inhibitory assay of Acacia catechu ethanolic seed

\begin{tabular}{|c|c|}
\hline \multicolumn{2}{|l|}{ AchE inhibitory assay } \\
\hline Concentration (ug/ml) & $\%$ inhibition \\
\hline 50 & 5 \\
\hline 100 & 10 \\
\hline 150 & 18 \\
\hline 200 & 25 \\
\hline 250 & 35 \\
\hline 300 & 45 \\
\hline IC50 Acacia catechu $=204.38= \pm 2.54(\mathrm{ug} / \mathrm{ml})$ & - \\
\hline $\mathrm{IC}_{50}$ Galantamine $=2.727= \pm 0.08(\mathrm{ug} / \mathrm{ml})$ & - \\
\hline
\end{tabular}

Acacia catechu Catechin produced promising result in cognitive enhancement in $\mathrm{AD}$ patients.

Hence, Ethanolic extract of Acacia catechu seed is investigated for its anti-cholinesterase inhibitory activity for the first time.

\section{MATERIALS AND METHODS}

\section{Plant material}

Acacia catechu seeds were collected from Hosur, Tamilnadu and was authenticated by Dr. H.B Singh, NISCAIR, New Delhi and the voucher specimen were stored for further use in Green Chem lab, Bangalore.

\section{Ethanolic Extraction}

Seeds were shade dried for a week. Dried seeds were milled to fine powder. Powder was passed through 100 mesh sieve and stored in a sealed polythene bag. $2.5 \mathrm{~kg}$ of powdered Acacia catechu seeds were extracted with 10 liters of Ethanol, at $65^{\circ} \mathrm{C}$ temperature, for 1 hour, in a 20 liter round bottom flask with Graham condenser attached. Condenser was cooled circulating with chilled water. After 1 hour of extraction, round bottom flask was cooled to room temp and the extract were filtered and collected. The Marc was extracted repeatedly with 10 liters of Ethanol, twice. The extracts were filtered and collected. The combined extracts was evaporated to dryness under reduced pressure in a Buchi Rotary Evaporator (Switzerland) at $65^{\circ} \mathrm{C}$, to obtain $150 \mathrm{~g}$ of powder extract. The w/w yield of the prepared extract was $6 \%$. The extract were stored at $4^{\circ} \mathrm{C}$ until used.

\section{Chemicals}

Acetylthiocholine iodide (ATCI), 5,5'-dithio-bis-2-nitrobenzoic acid (DTNB), bovine serum albumin (BSA) were purchased from Sigma (USA). Buffers and other chemical were of extra pure analytical grade. The following buffers were used: Buffer A:50 mM Tris-HCl, pH 8, containing 0.1\% BSA; Buffer B:50 mM Tris- $\mathrm{HCl}, \mathrm{pH} 8$ containing $0.1 \mathrm{M}$ $\mathrm{NaCl}, 0.02 \mathrm{M} \mathrm{MgCl}_{2} \times 6 \mathrm{H}_{2} \mathrm{O}$.

\section{Anti-cholinesterase inhibitory assay}

The AChE activity was measured according to the method developed by Eldeen et al. ${ }^{18,19}$ with slight modifications. To various concentrations of sample extracts $(50-250 \mu \mathrm{g} / \mathrm{ml}), 25 \mu \mathrm{l}$ of $15 \mathrm{mM}$ acetylthiocholine iodide (ATCI), $125 \mu$ of $3 \mathrm{mM}$ DTNB (5-5'-thiobis-2-nitrobenzoic acid) in Buffer $\mathrm{C}(50 \mathrm{mM}$ Tris- $\mathrm{HCl}, \mathrm{pH} 8$, containing $0.1 \mathrm{M} \mathrm{NaCl}$ and $0.02 \mathrm{M}$ $\mathrm{MgCl}_{2} .6 \mathrm{H}_{20}$ ) and $50 \mu \mathrm{l}$ of Buffer B (50 mM Tris- $\mathrm{HCl}, \mathrm{pH} 8$, containing $0.1 \%$ bovine serum albumin) were added. Thereafter, AChE $(0.2 \mathrm{U} / \mathrm{ml})$ was added and the final mixture was read at $405 \mathrm{~nm}$ immediately. Galantamine was used as a standard drug.

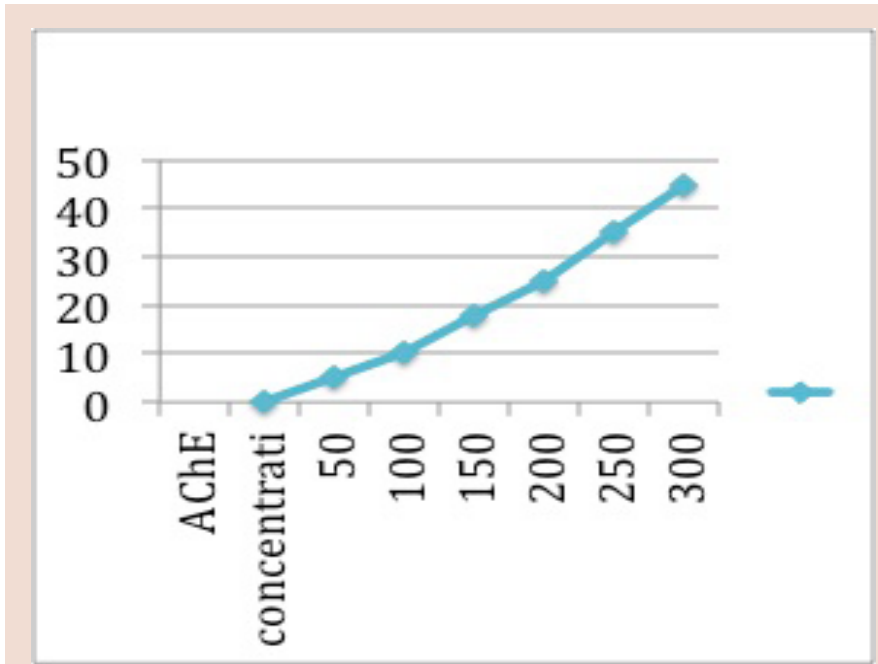

Figure 1: Acetyl choline inhibitory assay of $A$. catechu seed extract

\section{Determination of IC}

The percentage inhibition was then calculated using the following formula; $\%$ inhibition $=[($ Control OD - Sample OD $) /$ Control OD $] \times 100$

The experiment was done in triplicate and concentrations of the test extract that inhibit the hydrolysis of the substrate (acetylcholine) by $50 \%$ $\left(\mathrm{IC}_{50}\right)$ were determined by linear regression analysis between the inhibition percentage versus the extract concentration.

\section{RESULT AND DISCUSSION}

Neurodegenerative disease is a term applied to a variety of conditions arising from a chronic breakdown and deterioration of the neurons, particularly those of the central nervous system.

Alzheimer's disease is associated with loss of cholinergic neurons in the brain and the decreased level of AChE. The major therapeutic target in the $\mathrm{AD}$ treatment strategies is the inhibition of brain $\mathrm{AChE} .{ }^{20}$ Cholinesterase inhibitor drugs, inhibiting AChE activity, maintain ACh level by decreasing its breakdown rate. ${ }^{21}$ Although the underlying patho physiological mechanisms are not clear, $\mathrm{AD}$ is firmly associated with impairment in cholinergic pathway, which results in reduced level of acetylcholine (Ach) that is hydrolysed by cholinesterase (ChE) in certain areas of brain.

Medications currently approved by regulatory agencies such as the U.S. Food and Drug Administration (FDA) and the European Medicines Agency (EMA) to treat the cognitive manifestations of $\mathrm{AD}$ and improve life quality of the patients are Donepezil, rivastigmine and galantamine as reversible AChE inhibitors, and memantine as an NMDA receptor antagonist.

Tacrine was the first of the AChE inhibitors approved for the AD treatment in 1993, but its use has been abandoned because of a high incidence of side effects including hepatotoxicity. ${ }^{22-24}$

Plant based compounds have been used as cognition enhancers herbs like Withania somnifera, Centella asiatica, Curcuma longa, Bacopa monnieri, Convolvulus pluricaulis, Celastrus paniculatus, Nardostachys jatamansi have been reported to be used in management of cognitive impairment in Ayurvedic system of medicine..$^{25,26}$

Acetyl cholinesterase inhibitory activity is dose dependently increasing at a concentration ranging from $50 \mu \mathrm{g} / \mathrm{ml}$ to $300 \mu \mathrm{g} / \mathrm{ml}$ and when compared to standard Galanthamine the inhibitory activity is moderate even though the tested extract shows significant activity. The results are depicted in Table 1 and Figure 1 and can be used for treating neurodegenerative disorders. 
It was reported that the presence of Catechin, Epicatechin in Acacia cat$e c h u$ is responsible for treating cognitive impairment and the observed anti-cholinesterase activity found in the study could be due to the presence of Catechins, Quercetin and Epicatechin. ${ }^{27}$

\section{CONCLUSION}

The results concluded that Acacia catechu ethanolic seed extract exhibited potential acetyl cholinesterase inhibitory activity, further In vivo studies are required to prove its cognitive efficacy.

\section{ACKNOWLEDGEMENT}

The Authors wish to Thank Dr. Ezhilarasan Devaraj SR. Lecturer, Saveetha Dental College For his kind Support.

\section{REFERENCES}

1. Fratiglioni L, De Ronchi D, Agüero-Torres $H$. Worldwide prevalence and incidence of dementia. Drugs Aging 1999; 15(5): 365-75.

2. Hebert LE, Scherr PA, Bienias JL, et al. Alzheimer's Disease in the US Population: Prevalence Estimates Using the 2000 Census. Archives of Neurology 2003; 60(1): 1119-22.

3. Alzheimer's Association: Alzheimer's disease facts and figures. Alzheimers Dement 2010; 6(1): 158-94.

4. Jorm AF, Jolley D. The incidence of dementia: A meta analysis. Neurology 1998 51(3): 728-33

5. Mishra S, Palanivelu K. The effect of curcumin (turmeric) on Alzheimer's disease: An overview. Annals of Indian Academy of Neurology 2008; 11(1): 13-9.

6. Perry EK, Pickering AT, Wang WW, Houghton PJ, Perry NS. Medicinal plants and Alzheimer's disease: from ethnobotany to phytotherapy. J Pharm Pharmacol. 1999; 51(5): 527-34

7. Curcio CA, KemperT. Nucleus rape dorsalis in dementia of the Alzheimer type: Neuro fibrillary changes and neuronal packing density. J Neuropathol Exp Neurol. 1984; 43(4): 359-68.

8. Inestrosa N, Alvarez A, Garrido J, Calderon F. Alzheimer's Disease: Biology, Diagnosis and Therapeutics. London: John Wiley and Sons; 1997. 501-10.

9. Sivaraman Dhanasekaran, Panneerselvam Perumal, Muralidharan Palayan. In vitro Screening for Acetyl cholinesterase enzyme Inhibition potential and Antioxidant Activity of Extracts of Ipomoea aquatica Forsk: Therapeutic lead for Alzheimer's disease. J App Pharm Sci. 2015; 5(02): 012-6.

10. Thimmappa $S$, Anekonda P, Hemachandra Reddy. Can herbs provide a new generation of drugs for treating Alzheimer's disease. Brain Research Reviews 2005 50(1): 361-76.

11. Singh KN, Lal B. Note on traditional uses of Khair (Acacia catechu Willd.) by in- habitants of shivalik range of western Himalaya. Ethnobotanical Leaflets 2006; 10(1): 109-112.

12. Naik GH, Priyadarsini KI, Satav JG, Banavalikar MM, Sohoni DP, Biyani MK, et al. Comparative antioxidant activity of individual herbal components used in Ayurvedic medicine. Phytochemistry 2003; 63(1): 97-104.

13. Anonymous, Indian Herbal Pharmacopoeia. Revised new edition 2002, Indian Drug Manufacturer's Association, Mumbai 2002; 11(1): 13-6.

14. Lakshmi T, Anitha R, Geetha RV. Acacia catechu willd-A gift from ayurveda to mankind - A Review. T. Ph. Res. 2011; 5(2): 273-93.

15. Lakshmi T, Aravindkumar S. Preliminary phytochemical analysis, In vitro Antibacterial activity of Acacia catechu willd Bark against Streptococcus mitis Streptococcus sanguis and Lactobacillus acidophilus. International Journal of Phytomedicine 2011; 3(4): 579-84.

16. Evans WC. Trease and Evans' Pharmacognosy 14 Edn. W.B. Saunders Company, London; 1996.

17. Singh KN, Mittal RK, Barthwal KC. Hypoglycemic activity of Acacia catechu, Acacia suma, and Albizzia odoratissima seed diets in normal albino rats. Indian Journal of Medical Research 1976; 64(5): 754-7.

18. Ellman GL, Courtney D, Andres V, Featherston RM. A new and rapid colorimet ric determination of acetyl cholinesterase activity. Biochem Pharmacol. 1961; 7(2): 88-95

19. Eldeen IMS, Elgorashi EE, van Staden J. Antibacterial, anti-inflammatory, Anticholinesterase and mutagenic effects of extracts obtained from some tress used in South African traditional medicine. Journal of Ethnopharmachology 2005: 102(3): 457-64.

20. Mantle D, Pickering AT, Perry EK. Medicinal plant extracts for the treatment of dementia: A review of their pharmacology, efficacy and tolerability. CNS Drugs 2000; 13(3): 201-3.

21. Hachiro S, Yoshiharu Y, Youichilimura Y, Kawakami. Donepezil Hydrochloride (E2020) and Other Acetyl cholinesterase Inhibitors. Current Medicinal Chemistry 2000; 7(3): 303-39.

22. Zarotsky V, Sramek JJ, Culter NR. Galanthamine hydrobromide: an agent for Alzheimer's disease. Am J Health-System Pharmacist 2003; 60(5): 446-52.

23. Schneider LS. Treatment of Alzheimer's disease with cholinesterase inhibitors. Clin Geriatric Med. 2001; 17(2): 337-58.

24. Howes MR, Houghton PJ. Plants used in Chinese and Indian traditional medicine for improvement of memory and cognitive function. Pharmacol Biochem Behav. 2003; 75(3): 513-27.

25. Bakthira H, Awadh Ali NA, Arnold N, Teichert A, Wessjohann L Anticholinesterase activity of endemic plant extracts from soqotra. Afr J Tradit Complement Altern Med. 2011; 8(1): 296-9

26. Rao RV, Descamps O, John V, Bredesen DE. Ayurvedic medicinal plants for Alzheimer's disease: a review. Alzheimer's Research \& Therapy 2012; 4(3): 22.

27. Biradar SM, Tarak KC, Kulkarni VH, Habbu PV Smita DM. Antiamnesic and Antioxidant Effect of Acacia catechu-catechin in Normal, Aged and Scopolamine Challenged Cognitive Deficit Mice. Journal of Pharmacology and Toxicology 2012; 7(5): 231-41.

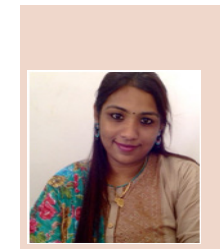

\section{ABOUT AUTHORS}

LakshmiThangavelu: Is an Assistant Professor at the Department of Pharmacology, Saveetha Dental College and Hospitals, SaveethaUniversity, Chennai, Tamilnadu, India. Her researchinterest includes Pharmacognosy, Pharmacology, Phytotherapy, Toxicology, and Pharmaceutical sciences. She has more than 50 nos. of Publications in peer reviewed indexed national and international journals. She is a peer reviewer in various journals. She is an editorial board member in International journal of pharmacy and pharmaceutical sciences, Internationale pharmaceutica sciencia, IBIMA publishers, USA. Ms. Lakshmi is also alife member of Indian pharmacological society, Society of Pharmaceutical education and research (SPER), Indian association of biomedical scientist (IABMS) and Society of Toxicology (STOX).

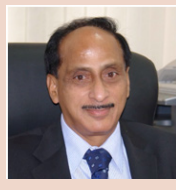

Rajendran Ramasamy: Is owing two herbal companies, Green Chem in Bangalore and Natsyn catalyst in Namakkal. He has done his post graduation in biochemistry. He is an eminent person holding about 26 patents globally on herbals. He has received more than 12 National/ International Awards to his credit. He also signed MOU with many Universities/colleges in India and abroad. He has more than 20 no. Paperpublications as an co-author in peer reviewed indexed national/international journals. He published a chapter "Role of Caralluma fimbriata in weight management" in a book "Obesity, Epidemiology, Pathophysiology and Prevention" by Debasis Bagchi, Harry G.Preuss (CRC Press), 2007. He also co authored for a book "Boswellin, The Anti Inflammatory Phytonutrient ", Published by Sabinsa Corporation, USA. 